\title{
Application of a Controlled Outside Cold Airflow by a PID Controller to Improve the Performance of a Household Refrigerator
}

\author{
Emna Aridhi ${ }^{1}$, Mehdi Abbes ${ }^{2}$, Abdelkader Mami ${ }^{1}$ \\ ${ }^{1}$ Université de Tunis El Manar, Ecole Nationale d'Ingénieurs de Tunis, LR11ES20 Laboratoire d'Analyse, de Conception \\ et de Commande des Systèmes (LACS), Faculté des Sciences de Tunis, 1002, Tunis, Tunisie \\ ${ }^{2}$ Université de Tunis El Manar, Ecole Nationale d'Ingénieurs de Tunis, LR11ES20 Laboratoire d'Analyse, de Conception \\ et de Commande des Systèmes (LACS), 1002, Tunis, Tunisie
}

\begin{tabular}{|c|c|}
\hline Article Info & ABSTRACT \\
\hline Article history: & \multirow{10}{*}{$\begin{array}{l}\text { The present paper aims to prove the efficiency of using the cold to improve } \\
\text { the performance of a household refrigerator. It is produced naturally in } \\
\text { countries that are characterized by a severe wintry climate. The cold airflow } \\
\text { is spread out inside a cavity covering the side wall of the appliance, which is } \\
\text { connected to the inlet and outlet ducts. For that purpose, a Simulink model is } \\
\text { proposed to model this installation. The internal air temperature is computed } \\
\text { according to the evaporator temperature and the outside cold airflow that is } \\
\text { also computed according to the outside temperature and controlled by a PID } \\
\text { controller. The simulation results show that when the internal air temperature } \\
\text { is higher than the desired one and the outside temperature is low enough, the } \\
\text { controlled cold airflow used as a second cooling source allowed to speed-up } \\
\text { the cooling inside the refrigerator compartment of about } 36.21 \% \text { and to reach } \\
\text { an energy saving of about } 36.23 \% \text { compared with the classical thermostatic } \\
\text { control. }\end{array}$} \\
\hline Received Jan 12, 2016 & \\
\hline Revised Mar 14, 2016 & \\
\hline Accepted Mar 25, 2016 & \\
\hline Keyword: & \\
\hline Cold airflow & \\
\hline Energy efficiency & \\
\hline PID Controller & \\
\hline Refrigerator & \\
\hline Renewable energy & \\
\hline
\end{tabular}

Copyright (C) 2016 Institute of Advanced Engineering and Science. All rights reserved.

\section{Corresponding Author:}

Emna Aridhi,

Department of Physics,

Université de Tunis El Manar, Faculté des Sciences de Tunis,

1002, Tunis, Tunisie.

Email: emna.aridhi@fst.rnu.tn

\section{INTRODUCTION}

Nowadays, the use of electricity in air-conditioning and refrigeration systems greatly increases seen that the comfort demand was accentuated and many products (food, chemical, etc.) have to be kept chilled. Indeed, they are estimated to be responsible for $15 \%$ of the global electricity consumption [1]. Furthermore, the conventional refrigeration cycles driven generally by the traditional vapor compression contributed significantly in an opposite way to the sustainable development concept, due to two major problems: the global increasing consumption of limited primary energy resources and the refrigerants used are harmful and cause serious environmental problems.

Recently, an increasing interest was concentrated on the technological development, and the harness of the renewable energy resources like the solar, geothermal, wind, etc. They are produced by natural resources, which are free and inexhaustible. These solutions can offer a reduction of the consumption, the demand and the cost of electrical energy without lowering the desired comfort level. For instance, the solar energy is extensively used in classical refrigeration installations driven by the vapor compression cycle (VCC). An energy saving of about 50\% was obtained [2]. Combined absorption-compression systems are also assisted by the renewable energy resources. Indeed, a cool chamber with a solar-driven absorption refrigerator was designed in [3]. It did not consume any electrical energy. The solar energy is strongly useful 
in the desert zones where the electricity is not easily available. Moreover, geothermal energy resource is also invested in refrigeration in many countries. For instance, in Tunisia, the vapor generation was made within a cooling system with vapor absorption, cascaded by a VCC. The installation allowed producing approximately 90 tons of ice per hour in order to preserve agricultural and fishing products [4]. Likewise, in Iceland, 70\% of the factories use the geothermal energy for industrial activities such as refrigeration and heating [5],[6].

The optimization of the refrigeration cycles also has a tremendous effect on the energy use. It aims to get rid definitively some refrigerants in future magnetic or thermo-acoustics refrigerators, which use sound waves to pump the heat [7]. Alternatively, it is carried out using advanced refrigeration techniques. For instance, the hybrid refrigeration cycle allowed an energy saving of about $52.7 \%$ compared with the VCC [8]. Furthermore, the novel household refrigerators with shape-stabilized PCM (Phase Change Material) heat storage condensers also concede an energy saving of about 12\% [9],[10]. The ventilation of the compressor surroundings allowed decreasing its temperature and then, reducing the energy consumption of about $9.17 \%$ [11]. On the other hand, several control algorithms were developed to optimize the cooling in the refrigeration systems like household refrigerators and to minimize the electrical energy use. Among them, many researchers have carried out adaptive [12],[13], fuzzy logic [14],[15], neural networks [14], and PID [16],[17] temperature control. Other studies were focused on Model-based Predictive Control (MPC) of the temperature inside the refrigerator compartment in order to reduce the energy use up to $30 \%$ [18] and $36 \%$ [19].

Beyond that, the very cold climate in high altitude regions persists over longer periods of the year. However, the cooling systems like refrigerators and cold storage are placed in locations where the ambient temperature is around $25^{\circ} \mathrm{C}$. Consequently, an energy wasting is caused. Hence, emerges the idea of using the free and abundant cold airflow to cool the refrigerator compartment through ducts, which connect the appliance to the cold outside surroundings.

In the present paper, the outside cold airflow is used as a second cooling source. It circulates in an inlet duct connected to a cavity covering the side wall of the refrigerator chamber through an inlet opening. At the exit, it is also connected to an outlet duct through an opening. The outside airflow is controlled using a PID controller in order to control the temperature inside the chamber. Thus, it allows improving the cooling process and also reducing the energy consumption.

The paper is organized as follows: Section 2 describes the installation to model. Section 3 presents the plants used in the model and which are determined by linearization of the pseudo bond graph model of the same installation. Section 4 is devoted to illustrating the control method using the Simulink environment. In section 5, the simulation results are present. Section 6 gives the conclusion.

\section{NOMENCLATURE}

$\begin{array}{lllll}\mathrm{C}_{\mathrm{p}} & \text { Specific heat capacity of air at } 0^{\circ} \mathrm{C} & \left(\mathrm{J}_{\mathrm{kg}} \mathrm{kg}^{-1} \cdot \mathrm{K}^{-1}\right) & \text { Abbreviations } & \\ \dot{\mathrm{m}} & \text { Mass flow } & & & \\ \mathrm{P} & \text { Pressure } & \left(\mathrm{kg} \cdot \mathrm{s}^{-1}\right) & \text { comp } & \text { Compressor } \\ \mathrm{T} & \text { Temperature } & (\mathrm{bar}) \text { or }(\mathrm{Pa}) & \text { evap } & \text { Evaporator } \\ \mathrm{V} & \text { Speed } & \left({ }^{\circ} \mathrm{C}\right) \text { or }(\mathrm{K})\left(\mathrm{m} \cdot \mathrm{s}^{-1}\right) & \text { init } & \text { initial } \\ \text { Vol } & \text { Volume } & \left(\mathrm{m}^{3}\right) & \text { out } & \text { outside/ outlet } \\ & & & \text { VCC } & \text { Vapor Compression Cycle }\end{array}$

\section{MODEL DESCRIPTION}

In the present paper, a controlled cold outside airflow is spread out at the side wall level of the appliance. This wall is covered with a cavity in which flows the cold air. This cavity is also connected to inlet and outlet ducts through two openings, see Figure 1 . It is rectangular, of size $0.814 \times 0.477 \times 0.1 \mathrm{~m}$ (height $\times$ length $\times$ width), and made of plastic. The inlet duct is a pyramid-shaped among which the width of the big and the small base is equal to 0.2 and $0.1 \mathrm{~m}$, respectively. However, the outlet duct is rectangular. Both ducts are 3-meters length and also made of plastic. Furthermore, the thickness of walls is $3 \mathrm{~mm}$. 


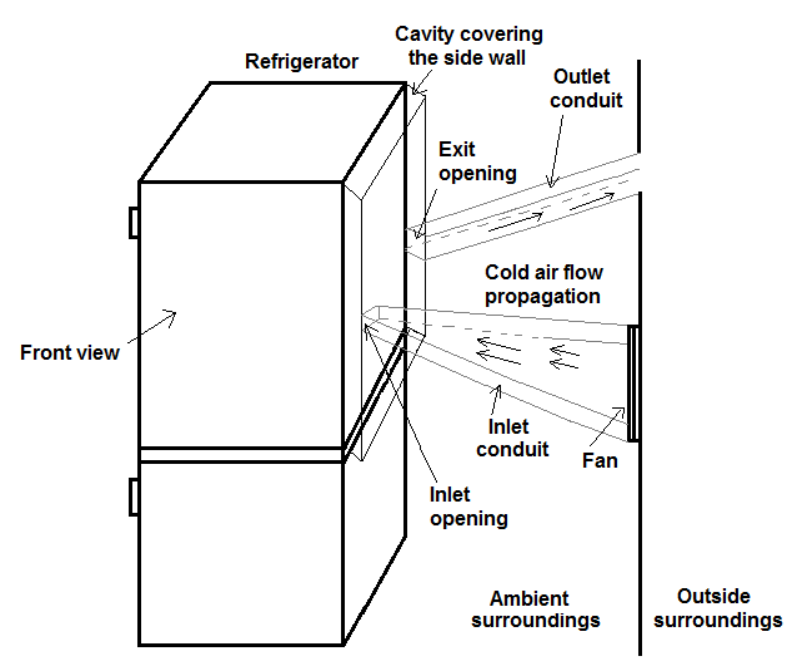

Figure 1. Outside cold airflow diffusion at the side wall level of the refrigerator compartment

Moreover, we suppose that the cold airflow stemming from the outside surroundings is pushed by a small fan and in the simulation, we admit two outside airflow temperature values: $-20^{\circ} \mathrm{C}$ and $18^{\circ} \mathrm{C}$. The first one corresponds to the wintry climate in high altitude countries like in Canada.

\section{PLANTS} Figure 2.

The installation depicted in Figure 1 was modeled using the bond graph approach. It is sketched in

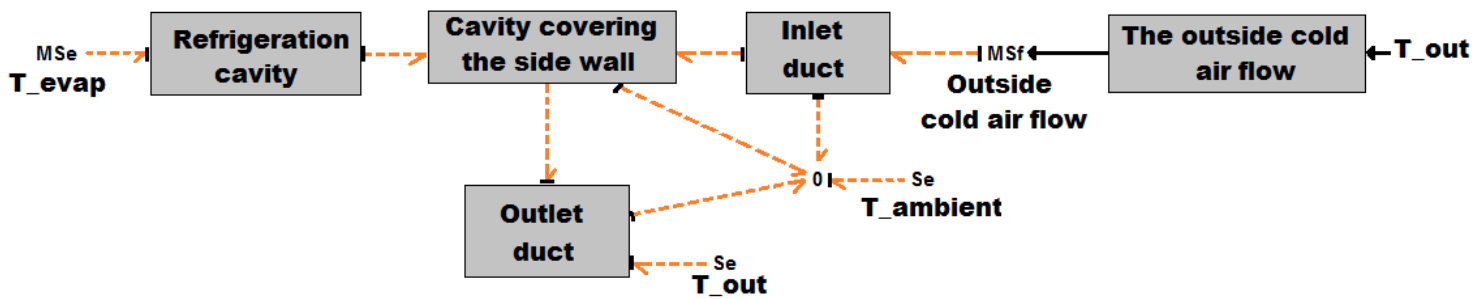

Figure 2. Pseudo bond graph model of thermal transfers between the refrigeration cavity and the outside cold airflow

The 'Refrigeration cavity' block is the pseudo bond graph model of thermal transfers by natural convection inside the cooling compartment [20]. It computes the internal air temperature according to the temperature at the evaporator wall level $T$ evap under the influence of the ambient temperature $T$ ambient. The 'Outside cold air flow' block computes the outside flow according to the outside temperature $\bar{T}$ out and the mass flow. The 'Inlet duct', the 'Outlet duct' and the 'Cavity covering the side wall' blocks model the thermal transfers inside the inlet duct, the outlet duct and the cavity covering the side wall, respectively, under the influence of the ambient temperature $T$ _ambient and the outside temperature $T$ _out .

To control the temperature inside the cooling compartment, the pseudo bond graph model should be linearized around the operating point $\left(\mathrm{T}_{0}=25.1^{\circ} \mathrm{C}\right)$, for an ambient temperature value equal to $25^{\circ} \mathrm{C}$. The linearization gives two continuous transfer functions: $\mathrm{H}_{2}$ calculates the internal air temperature according to the temperature at the evaporator wall level, and $\mathrm{H}_{3}$ calculates it according to the controlled outside cold airflow.

$$
H_{2}(p)=\frac{T_{\text {Internal }}(p)}{T_{\text {evap }}(p)}=\frac{1.004 p^{5}+0.005067 p^{4}+0.08148 p^{3}+0.03008 p^{2}+0.00103 p}{p^{6}+11.57 p^{5}+18.68 p^{4}+6.991 p^{3}+0.2808 p^{2}+0.001311 p}
$$




$$
H_{3}(p)=\frac{T_{\text {Internal }}(p)}{\text { Flow_out }(p)}=\frac{3.84 .10^{-6} p^{2}+2.727 .10^{-6} p}{p^{6}+11.57 p^{5}+18.68 p^{4}+6.991 p^{3}+0.2808 p^{2}+0.001311 p}
$$

The system rank is the number of $\mathrm{C}$ elements of the pseudo bond graph model in integral causality (here 6). Furthermore, the temperature at the evaporator wall level $T_{\text {evap }}$ was computed according to the compressor speed $V_{\text {comp }}$ using the following continuous transfer function $\mathrm{H}_{1}$ that was obtained by the System Identification Toolbox. It is worth noting that the behavior of this temperature according to the compressor speed is similar to that of a first-order system.

$$
H_{1}(p)=\frac{T_{\text {evap }}(p)}{V_{\text {comp }}(p)}=\frac{-6.558 .10^{-6}}{p+0.0001509}
$$

\section{TEMPERATURE CONTROL INSIDE THE REFRIGERATOR COMPARTMENT}

In this section, a PID controller is used to control the outside cold airflow in order to control the temperature inside the cabinet.

\subsection{Conventional On/Off control}

In the most cooling systems, the compressor is driven by a classical thermostatic control. According to the thermostat power adjustment, the internal air temperature varies in an interval $\left[\mathrm{T}_{\min }, \mathrm{T}_{\max }\right]$. When it exceeds $T_{\max }$, the compressor switches on. It stops if the internal temperature becomes lower than $T_{\min }$.

\subsection{PID controller}

The control loop of the outside cold airflow and thus of the internal temperature is illustrated in Figure 3

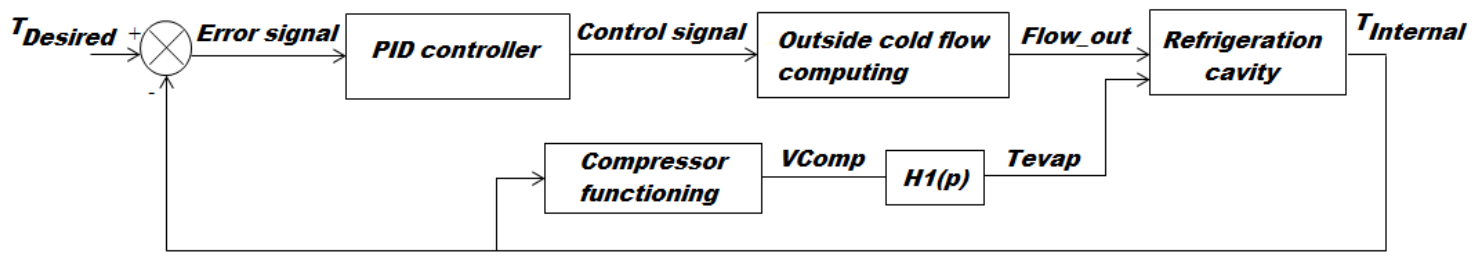

Figure 3. PID controller based closed-loop temperature control inside the cabinet

The 'Compressor functioning' block is used to specify the value of the compressor speed ' $V_{\text {comp }}$ ' $(0$ or $50 \mathrm{~Hz}$ ) according to the variation of the internal air temperature $T_{\text {Internal }}$. The controlled outside airflow 'Flow_out' spread out at the wall level of the refrigerator compartment is computed in (4), according to the mass flow $\dot{m}$ that is also computed according to the control signal using (5).

$$
\text { Flow_out }=\dot{m} \cdot C_{p} \cdot T_{-} \text {out }
$$

with $C p$ is the specific heat capacity of air at $0^{\circ} \mathrm{C}, T_{-}$out is the outside temperature and $\dot{m}$ is calculated in (5).

$$
\dot{m}=\left(\frac{\text { control_signal }}{R_{s}}\right) \cdot \operatorname{sign}(\Delta P) \cdot \sqrt{|\Delta P|}
$$

Here, $R_{S}$ is the hydraulic resistance, which characterizes the pressure drop and $\Delta P$ is the pressure difference in the inlet and outlet ducts. The PID equation is written in (6).

$$
C_{P I D}(p)=K_{p}+\frac{K_{i}}{p}+K_{d} \frac{N}{1+N \frac{1}{p}}
$$


where, $\mathrm{K}_{\mathrm{p}}=43500, \mathrm{~K}_{\mathrm{i}}=18.25$, and $\mathrm{K}_{\mathrm{d}}=4.56$. They were determined using the Ziegler-Nichols method of the critical point [21]. The parameter $\mathrm{N}$ is equal to 100 .

\subsection{Simulink model}

In this section, a Simulink model of the internal air temperature control is proposed. It is depicted in Figure 4.

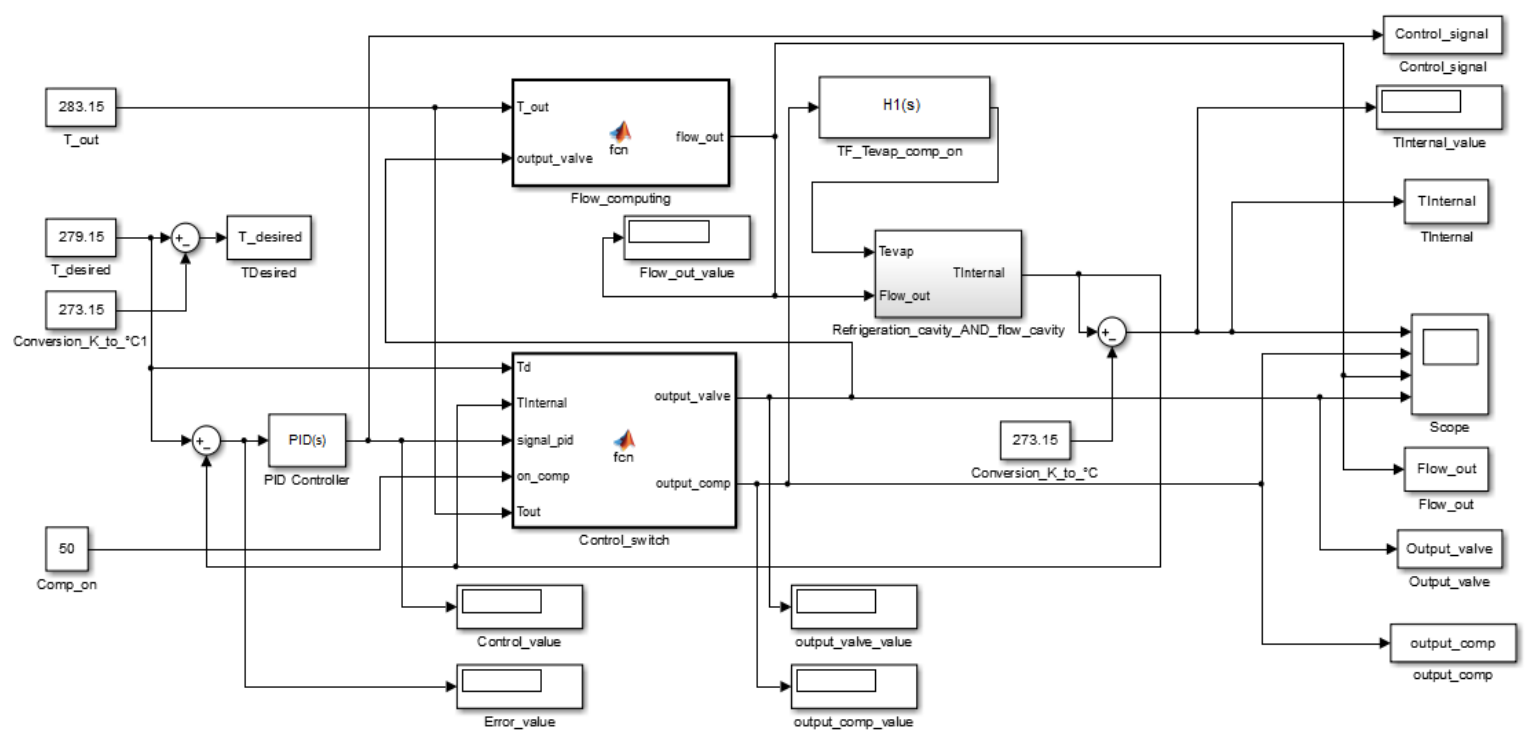

Figure 4. Simulink model of the temperature control inside the refrigerator compartment

The controlled cold airflow is computed using the 'Flow_computing' Matlab function. As for the internal air temperature, it is calculated according to the controlled outside airflow Flow out and the temperature at the evaporator wall level Tevap using the theorem of superposition. The Simulink model of the refrigeration cavity 'Refrigeration_cavity_AND_flow_cavity' is depicted in Figure 5.

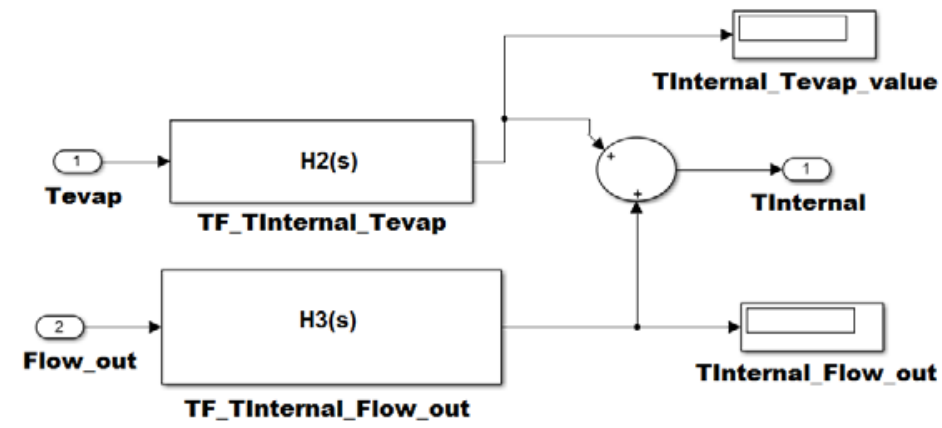

Figure 5. Simulink model of the refrigeration cavity

The temperature at the evaporator wall level Tevap depends on the switching cycles. Indeed, in the model, the stop and the switching on of the compressor correspond to 0 and $50 \mathrm{~Hz}$, respectively. This behavior depends on the internal air temperature value and is modeled by the 'output_comp' signal. The Matlab function 'Control_switch' is added to the model in order to specify in which case the compressor switches on and stops. It also indicates when the controlled outside cold airflow is used to cool the side wall of the cabinet. In fact, several scenarios can occur according to the value of the outside temperature $T \_$out, the internal temperature $T_{\text {Internal }}$, and the desired temperature $T_{\text {Desired }}$ : 
- If $T_{\text {Internal }}<$ or $=T_{\text {Desired }}$, the compressor is stopped and the outside airflow is not applied to the side wall of the appliance. However, this controlled second cooling source is used to maintain the internal air temperature near the desired one.

- If $T_{\text {Internal }}>T_{\text {Desired }}$ and $T_{\text {_out }}<T_{\text {Desired, }}$, the compressor switches on and the outside air is used for the cooling. In this case, it allowed to speed-up the cooling compared with the classical thermostatic control. Hence, the duration of the compressor functioning is reduced. Consequently, the electrical energy would be saved.

- If $T_{\text {Internal }}>T_{\text {Desired }}$ and $T$ _out $>T_{\text {Desired, }}$, the outside airflow will not be able anymore to cool the side wall of the fridge, especially, when $T$ out exceeds $15^{\circ} \mathrm{C}$.

The control signal 'signal_pid' is assigned to the 'output_valve' signal, which allows computing the outside cold airflow.

\section{RESULTS AND DISCUSSION}

During the simulation, The initial value $T_{\text {Init }}$ of the internal air temperature is chosen according to the following cases. The desired temperature is equal to $6^{\circ} \mathrm{C}$. When the internal temperature reaches this value, the compressor switches off, and when it is exceeded, the compressor switches on.

\subsection{Case of $T_{\text {Internal }}>T_{\text {Desired }}$ and $T_{-}$out $=-20^{\circ} \mathrm{C}$}

In this case, the appliance is turned on. Therefore, $T_{\text {Init }}$ is chosen equal to $25.1^{\circ} \mathrm{C}$. The simulation was performed during 4hours (14400s). The simulation results of the Simulink model show that the internal air temperature reached the desired one after about $2 \mathrm{~h}$ and $13 \mathrm{~min}$ (approximately 8000s), for which the compressor is turning on (the 'output_comp' signal is assigned to $50 \mathrm{~Hz}$ ), and the controlled outside cold airflow is applied to the side wall of the appliance. The internal air temperature behavior and the compressor functioning are both illustrated in Figure 6 and Figure 7, respectively.

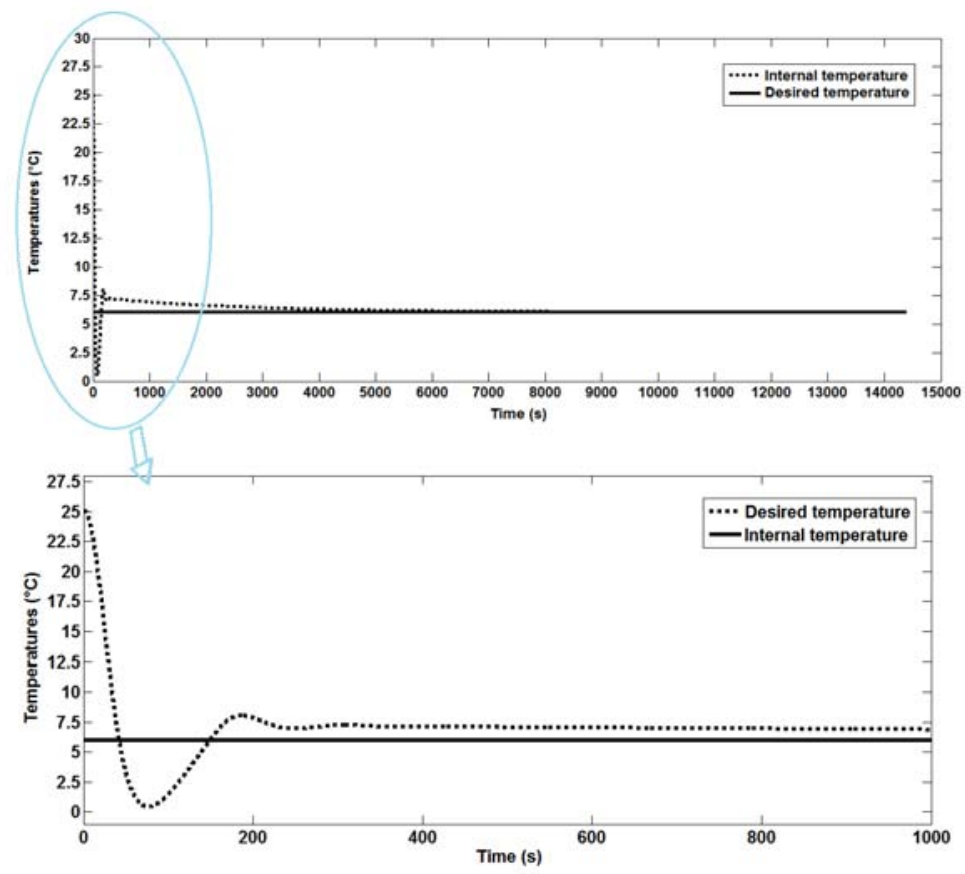

Figure 6. Impact of the controlled outside cold airflow on the internal air temperature 


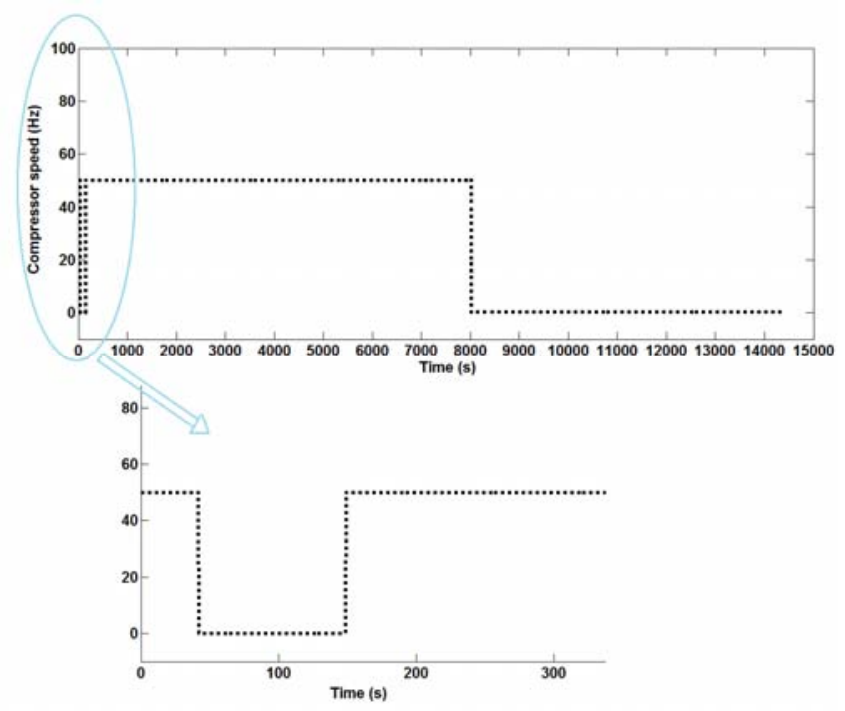

Figure 7. Impact of the controlled outside cold airflow on the compressor functioning

As shown in Figure 7, the internal air temperature decreased to $0.46^{\circ} \mathrm{C}$ during approximately $3 \mathrm{~min}$. At the same time, the compressor was switched off, which allowed an energy saving of about $1.25 \%$. After that, the internal air temperature was increased to $6^{\circ} \mathrm{C}$, due to the action of the PID controller. The curves of the outside airflow and the 'Output_valve' signal are enlarged and plotted in Figure 8. It is noted that the cold airflow value was stabilized at about $-7.5 \mathrm{~kJ} . \mathrm{s}^{-1}$.

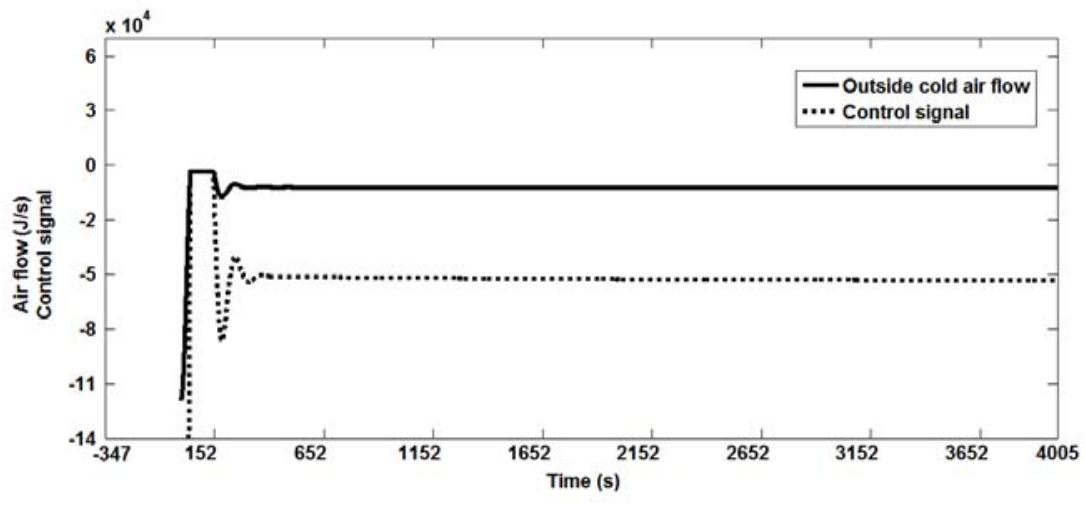

Figure 8. The profile of the controlled outside cold airflow and the control signal 'Output_valve'

In the normal operating conditions without the support of the outside cold airflow, the internal air temperature takes about $3 \mathrm{~h}$ and $29 \mathrm{~min}$ to reach the desired temperature [20]. While in the present case, it only takes $2 \mathrm{~h}$ and $13 \mathrm{~min}$, for which the rate of the compressor functioning is about $63.77 \%$. Therefore, the outside airflow allowed accelerating the cooling of about $36.21 \%$ during $3 \mathrm{~h}$ and $29 \mathrm{~min}$. Thus, an energy saving of about $36.23 \%$ is achieved, for which, the compressor is switched off during $1 \mathrm{~h}$ and $16 \mathrm{~min}$. It is important to note that the refrigeration system is not disturbed. It means that the cold outside air temperature, and the ambient one are constant during the simulation. Hence, the compressor remains at rest after the achievement of the desired temperature. The comparison results of the internal air temperature behavior, in normal operating conditions and with the presence of the cold outside airflow, are shown in Figure 9. 


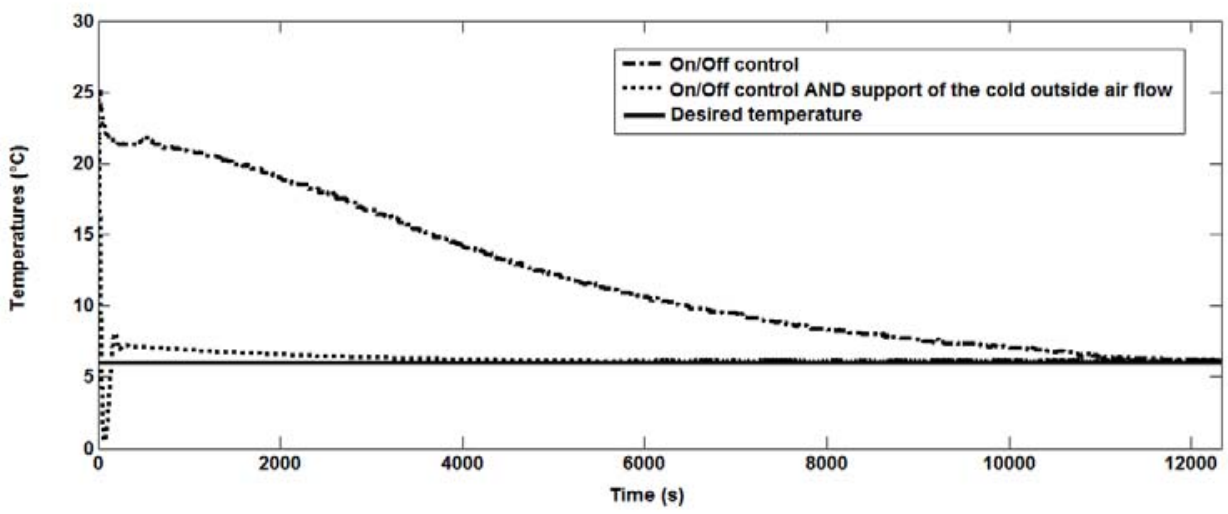

Figure 9. Internal air temperature behavior with and without the support of the controlled outside cold airflow

\subsection{Case of $T_{\text {Internal }}>T_{\text {Desired }}$ and $T_{-}$out $=18^{\circ} \mathrm{C}$}

In this case, the initial temperature $T_{\text {Init }}$ is chosen equal to $15^{\circ} \mathrm{C}$ (The appliance is operating). Here, the outside cold airflow was not used forasmuch as the outside temperature is higher than $15^{\circ} \mathrm{C}$. The simulation duration is 4hours $(14400 \mathrm{~s})$, and the results obtained indicate that the internal air temperature took about one hour and $37 \mathrm{~min}$ to reach the desired one, see Figure 10. In this case, there is not an improvement in the cooling efficiency or a reduction of the energy consumption.

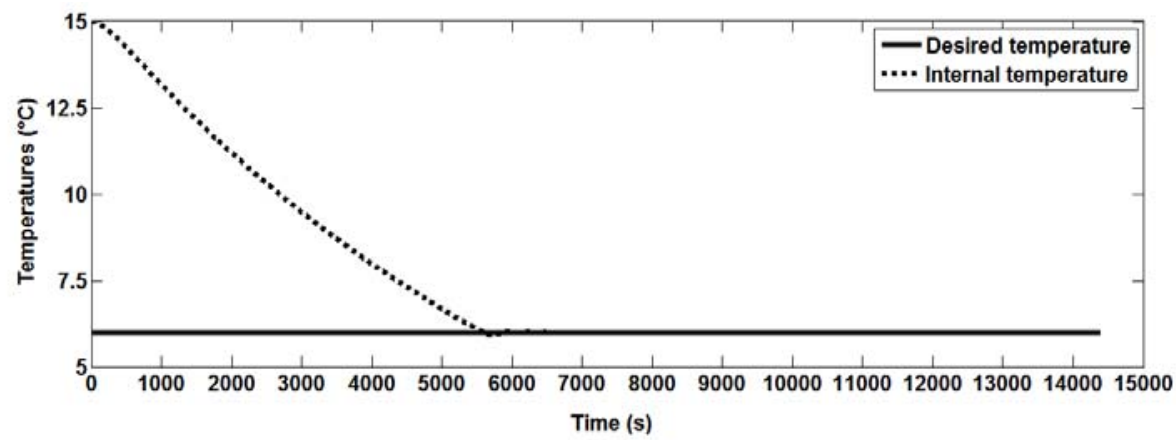

Figure 10. Internal air temperature profile when the controlled outside cold airflow was not used

Moreover, Figure 11 illustrates the compressor functioning.

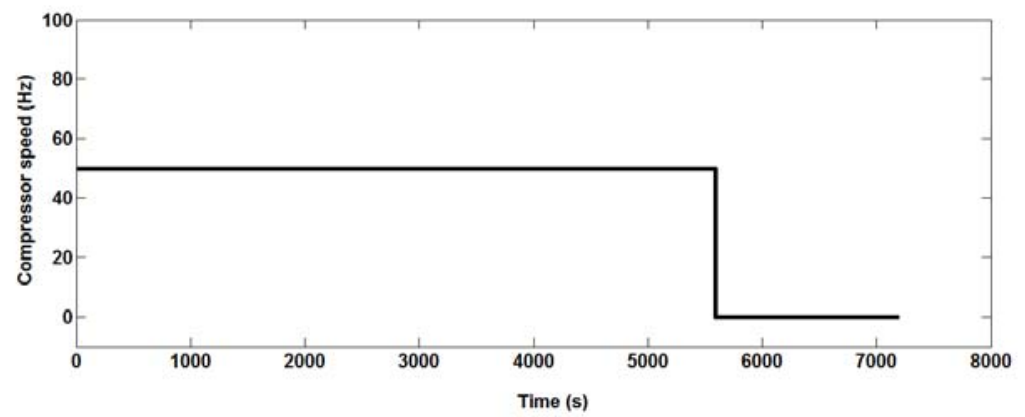

Figure 11. The compressor operation when the controlled outside cold airflow was not used 


\subsection{Case of $\mathbf{T}_{\text {Internal }}<$ or $=\mathbf{T}_{\text {Desired }}$}

In this case, the initial temperature $T_{\text {init }}$ is chosen equal to $5^{\circ} \mathrm{C}$ (lower than $T_{\text {Desired }}$ ). Consequently, the two cooling sources (the compressor and the controlled outside cold airflow) are inactive. Thus, the refrigerator does not consume energy. Nonetheless, it is important to clarify that in the Simulink model, this situation makes the internal air temperature equal to the initial temperature $T_{\text {init }}$. This behavior runs contrary to what is happening in the real case. Indeed, the internal air temperature is increasing seen that the cooling sources are both inactive. To remedy this, a continuous transfer function $\mathrm{H}_{4}$ was used and defined in (7).

$$
H_{4}(p)=\frac{2.774}{p+2.771}
$$

It models the internal air temperature profile when the compressor is not running and is determined by the System Identification Toolbox. In fact, it calculates the internal air temperature $T_{\text {Internal }}$ according to the temperature at the evaporator wall level $T_{\text {evap }}$. The changes made to the Simulink model of the cooling compartment (Figure 5) are depicted in Figure 12.

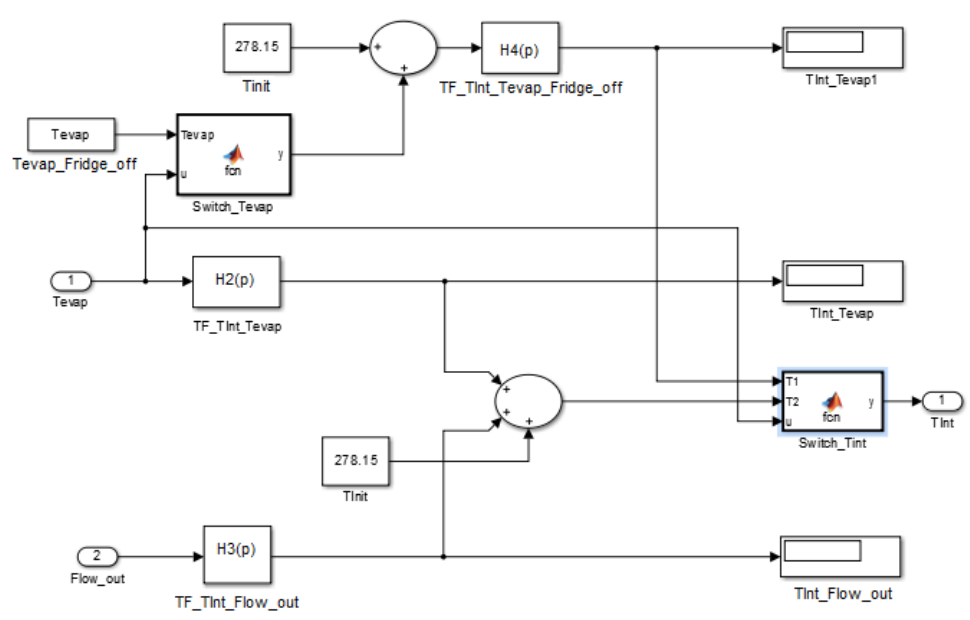

Figure 12. Complete Simulink model of the cooling compartment

In the Simulink model, the Matlab functions 'Switch_Tevap' and 'Switch Tint' have been added in order to test the value of the temperature at the evaporator wall level as follows: if this temperature is equal to zero, the transfer function $\mathrm{H}_{4}$ is used to compute the temperature in the refrigerator. Otherwise, it is computed using the transfer functions $\mathrm{H}_{2}$ and $\mathrm{H}_{3}$, see Figure 5. The results achieved for an hour are illustrated in Figure 13.

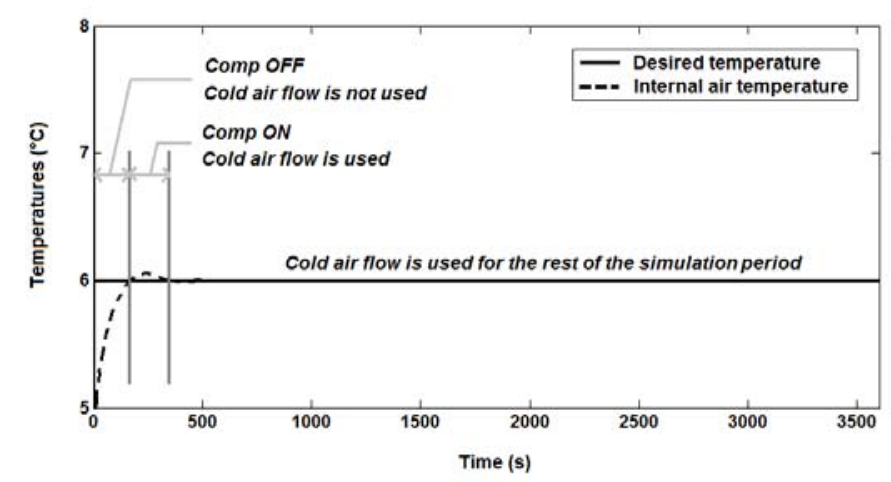

Figure 13. Internal air temperature profile when it is lower than the desired temperature 
From the results obtained, it is noted that the internal air temperature reached the desired one $\left(6^{\circ} \mathrm{C}\right)$ after approximately $2 \mathrm{~min}$. When it exceeded $6^{\circ} \mathrm{C}$, the compressor was switched on to decrease it. In this case, the controlled outside cold airflow will be used only if its temperature is lower than $15^{\circ} \mathrm{C}$. Indeed, these simulation results are achieved for an outside temperature $T \_$out equal to $-20^{\circ} \mathrm{C}$. Hence, during the rest of the simulation period, the internal air temperature was stabilized at $6^{\circ} \mathrm{C}$, which allows the switching off of the compressor.

\section{CONCLUSION}

The current work investigates the impact of an outside cold airflow on the cooling process and the efficiency of a household refrigerator. It can be considered as a significant promising solution for the environmental and energy-related issues, especially in high altitude countries where the climate conditions are very favorable to produce the cold freely. The simulation results of the Simulink model show that when the internal air temperature is higher than the desired one and the outside temperature is enough low, the controlled outside cold airflow allows to improve the appliance performance of about $36 \%$. In addition, the effect of the outside cold airflow begins to be less significant as the outside temperature becomes high. Moreover, the internal air temperature behavior was also modelled when the fridge is turned off.

\section{ACKNOWLEDGEMENTS}

The authors wish to thank the Laboratory team of Energy Performance of Refrigerators in the Technical Center of Mechanical and Electrical Industries in Tunis for his help to carry out the experiment on the refrigerator without any second cooling source.

\section{REFERENCES}

[1] A. C. Marques, et al., "Novel design and performance enhancement of domestic refrigerators with thermal storage," Applied Thermal Engineering, vol. 63, pp. 511-519, 2014.

[2] H. M. Henning, et al., "The potential of solar energy use in desiccant cooling cycles," International Journal of Refrigeration, vol. 24, pp. 220-229, 2001.

[3] Md. P. Islam and T. Morimoto, "A new zero energy cool chamber with a solar-driven adsorption refrigerator," Renewable Energy, vol. 72, pp. 367-376, 2014.

[4] L. Kairouani and E. Nehdi, "Cooling performance and energy saving of a compression-absorption refrigeration system assisted by geothermal energy," Applied Thermal Engineering, vol. 26, pp. 288-294, 2006.

[5] I. Sarbu and C. Sebarchievici, "Review of solar refrigeration and cooling systems," Energy and Buildings, vol. 67, pp. 286-297, 2013.

[6] H. Shahinzadeh and H. Ghotb, "Technical and Economic Assessment for using Ground-Source Heat Pumps in Commercial and Institutional Buildings," International Journal of Electrical and Computer Engineering (IJECE), vol. 2, pp. 502-510, 2012

[7] M. Nouh, et al., "Piezo-driven thermoacoustic refrigerators with dynamic magnifiers," Applied Acoustics, vol. 83, pp. 86-99, 2014.

[8] X. Menga, et al., "Energy saving mechanism analysis of the absorption-compression hybrid refrigeration cycle," Renewable Energy, vol. 57, pp. 43-50, 2013.

[9] W. Cheng and X. Yuan, "Numerical analysis of a novel household refrigerator with shape-stabilized PCM (phase change material) heat storage condensers," Energy Journal, vol. 59, pp. 265-276, 2013.

[10] X. Yuan and W. Cheng, "Multi-objective optimization of household refrigerator with novel heat-storage condensers by Genetic algorithm," Energy Conversion and Management, vol. 84, pp. 550-561, 2014.

[11] F. A. Clito, "Household refrigerators: Forced air ventilation in the compressor and its positive environmental impact," International Journal of Refrigeration, vol. 36, pp. 904-912, 2013.

[12] M. Di Felice, et al., "Adaptive Temperature Control of a Household Refrigerator," 2009 American Control Conference, pp. 889-894, 2009.

[13] K. Wait, "Adaptive temperature control of a class of home refrigerators," 2012 American Control Conference, pp. 380-385, 2012.

[14] B. J. Choi, et al., "Refrigerator temperature control using fuzzy logic and neural network," 1998 IEEE International Symposium on Industrial Electronics, vol. 1, pp. 186-191, 1998.

[15] M. Mraz, "The design of intelligent control of a kitchen refrigerator," Mathematics and Computers in Simulation, vol. 56, pp. 259-267, 2001.

[16] N. H. A. Hamid, et al., "Application of PID Controller in Controlling Refrigerator Temperature," 2009 International Colloquium on Signal Processing \& Its Applications, pp. 381-384, 2009.

[17] G. Qin, et al., "Design of Fuzzy Adaptive PID Temperature Controller Based on FPGA," TELKOMNIKA Indonesian Journal of Electrical Engineering, vol. 11, pp. 6008-6016, 2013.

[18] T. Hovgaard, et al., "Nonconvex Model Predictive Control for Commercial Refrigeration," International Journal of Control, vol. 86, pp. 1349-1366, 2013. 
[19] S. E. Shafiei, et al., "A supervisory control approach in economic MPC design for refrigeration systems," 2013 European Control Conference, 2013

[20] E. Aridhi, et al., "Pseudo bond graph model of thermal transfers sustained by ice quantity of a domestic refrigerator for energy saving application," IEEJ Transactions on Electrical and Electronic Engineering, vol. 10, pp. 308-319, 2015.

[21] J. M. Flaus, "La régulation industrielle (régulateurs PID, prédictifs et flous)," 1994.

\section{BIOGRAPHIES OF AUTHORS}
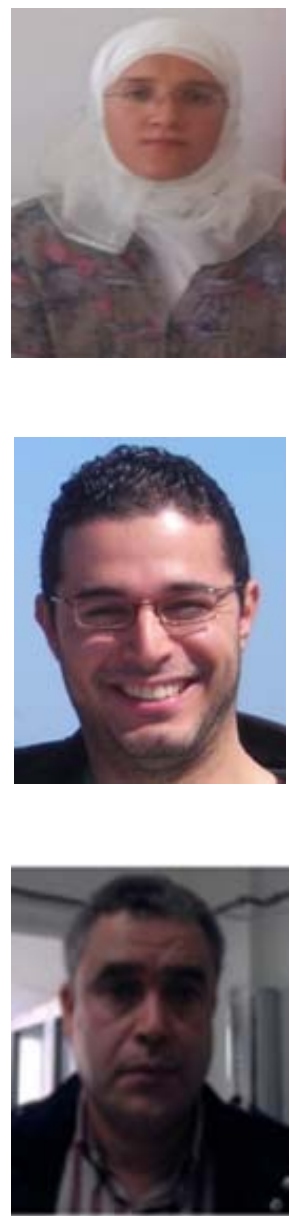

Emna Aridhi was born in Tunis, Tunisia, in 1986. She received the Ph.D. degree in Electronics from the Faculty of Sciences of Tunis (FST) in 2015. She works on the modelling using bond graph approach of cooling systems and the implementation of control algorithms of industrial processes on FPGA targets, in the Laboratory of Analysis, Design and Control Systems (LACS) at the National School of Engineering of Tunis (ENIT).

Mehdi Abbes was born in Paris, France, in 1978. He received the B.Sc. degree in Electronics and Instrumentation from the High School of Sciences and Techniques of Tunis, the M.Sc. degree in Measurements and Instrumentation from the High Institute of Applied Sciences and Technology, Tunis, and the Ph.D. degree in Electrical Engineering from the National School of Engineering, Tunis, in 2001, 2004 and 2009, respectively. He is currently an Assistant Professor at the High School of Sciences and Technology, Hammam-Sousse, Tunisia. His main research interests include bond graph modeling of thermos-fluid systems, reduction order methods for large-scale systems, and control algorithms in microelectronics.

Abdelkader Mami was born in Tunisia. He received his Dissertation H.D.R (Enabling To Direct Research) from the University of Lille, France, in 2003. He is currently a Professor at the Faculty of Sciences of Tunis (FST) and a Scientific Advisor in the Faculty of Science of Tunis (Tunisia). He is a President of the commutated thesis of electronics in the Faculty of sciences of Tunis, and the person responsible for the research group of analysis and command systems in the ACS laboratory, ENIT, Tunis. 